\title{
Navigating the Doctoral Experience: The Role of Social Support in Successful Degree Completion
}

\author{
Dharmananda Jairam and David H. Kahl, Jr. \\ Penn State University - Erie, Erie, PA, USA \\ duj11@psu.edu; dhk10@psu.edu
}

\begin{abstract}
This study investigated the role of social support in the successful completion of a doctoral degree. Thirty-one participants with earned doctoral degrees completed an open-ended qualitative survey. The researchers asked the participants to describe the behaviors from their social support network that both helped and hindered their degree completion. The findings lend support for the stress-buffer hypothesis and show that all three sources of social support (i.e., academic friends, family, and faculty) provide positive and negative support. The findings suggested the following recommendations for future doctoral students: a) aligning themselves with a small group of academic friends and preparing for the inevitable peer competition, b) seeking assistance from family members on certain tasks and educating family members on the doctoral student experience, and c) establishing good rapport with a doctoral adviser who is professionally active. Results also suggest recommendations for doctoral advisers, including awareness of how negative communication among faculty impacts doctoral students and the need to stay professionally active and maintain professional connections. Finally, limitations to this study and directions for future research are discussed.
\end{abstract}

Keywords: doctoral education, doctoral experience, social support, stress-buffer hypothesis

\section{Introduction}

The doctoral degree is considered the pinnacle of education, and it is pursued by nearly 100,000 students in the U.S. (Carnegie Classification, n.d.). Doctoral students are among the best and brightest students, having championed the highly competitive selection process (Ali \& Kohun, 2006; Gilliam \& Kitronis, 2006). However, 50\% of doctoral students will not finish their degree (Walker, Golde, Jones, Bueschel, \& Hutchings, 2008), and 40,000 drop out every year (Ali \& Kohun, 2007). In fact, many leave their programs in the first year (Esping, 2010; Lovitts, 2001). Doctoral student attrition is a silent epidemic in the U.S. (Ali \& Kohun, 2007; Lovitts, 2001).

Through empirical investigation, researchers have found that doctoral student attrition is linked to two main factors, stress (Lovitts, 2001) and feelings of social isolation (Ali \& Kohun, 2006;

Material published as part of this publication, either on-line or in print, is copyrighted by the Informing Science Institute. Permission to make digital or paper copy of part or all of these works for personal or classroom use is granted without fee provided that the copies are not made or distributed for profit or commercial advantage AND that copies 1) bear this notice in full and 2) give the full citation on the first page. It is permissible to abstract these works so long as credit is given. To copy in all other cases or to republish or to post on a server or to redistribute to lists requires specific permission and payment of a fee. Contact Publisher@InformingScience.org to request redistribution permission.
Hawlery, 2003; Lewis, Ginsberg, Davies, \& Smith, 2004). First, with regard to stress, doctoral students typically "...face enormous demands upon their time, energy, intelligence, endurance, patience, and organizational skills" (Committee on the College Student, 2000, p. 1); all of which heighten their stress level. Greater stress is experienced when it involves multiple and persistent stressors, rather than a single 
event (Cohen \& Wills, 1985). Doctoral students are significantly more stressed than the general public, and they report that their stress is mainly attributed to their graduate programs (Cahir \& Morris, 1991). The stressors of doctoral study include relative poverty, anxiety, sleeplessness, academic demands, fear of failure, examinations, and time constraints (Bowman \& Bowman, 1990; Esping, 2010). Additionally, doctoral students also find themselves having to manage the socialization into their new roles, building and maintaining new relationships, and creating their professional identity (Golde, 1998; Lee, 2009; Weidman, Twale, \& Stein, 2001). Because of these demands placed on doctoral students, their stress levels persist, and even increase, as they progress through their programs (Cahir \& Morris, 1991).

The second factor linked to doctoral student attrition is the feeling of social isolation, which refers to the absence of meaningful social connections (Hortulanus, Machielse, \& Meeuwesen, 2006; Lovitts, 2001). The social connections that are important for doctoral students include those with fellow students, faculty members, and their superiors (Ali \& Kohun, 2007). Feelings of social isolation stem from confusion about program expectations and miscommunication (or a lack of communication) with their peers and faculty (Ali \& Kohun, 2006; Lovitts, 2001). Social isolation is often exacerbated by being in a new, unfamiliar, and stressful environment, all of which are traits common to doctoral programs (Ali \& Kohun, 2007; Lovitts, 2001).

\section{Literature Review}

\section{Social Support}

A construct termed social support can offer doctoral students a sense of refuge by reducing both stress and feelings of social isolation (Ali \& Kohun, 2006; Hadjioannou, Shelton, Fu, \& Dhanarattigannon, 2007). Social support typically stems from people to whom one is socially tied (e.g., family members and friends) and is defined as what they "say and do regarding stressful events" (Lakey \& Orehek, 2011, p. 482). A social support network is comprised of several individuals within one's environment who influence one's perceptions of his or her environment and might include family members, friends, and co-workers (Kelly, 2005). Social support can take various forms, including emotional support (attempts to alleviate negative affect), professional support (mentoring and guidance), and practical support (money or help with task completion) (Heller \& Rook, 1997; House, 1981; Nelson \& Brice, 2008; Rosenholtz, 1989; Schaefer, Coyne, \& Lazarus, 1981; Singh \& Billingsley, 1998). Therefore, social support can mediate stress (Dirks \& Metts, 2010; Stachour, 1998).

\section{Social Support as a Mediator of Stress}

Several decades of stress-related research has consistently shown that stress has damaging effects on one's physical and psychological health (Kasl, 1984; Schnurr \& Green, 2004; Thoits, 2010). However, social support can help reduce stress. Both the quantity and quality of social support matter in reducing stress. Generally, individuals who receive more frequent and stronger social support have less stress, less physical and psychological problems, and lower mortality rates than those with less frequent and weaker social support (Berkman 1995; Jackson, 1992; Reblin \& Uchino, 2008; Stachour, 1998). The stress-buffer hypothesis is an emergent response to a specific stressor that explains how the impact of stress is reduced (Cohen \& Wills, 1985; Dirks \& Metts, 2010; Mallinckrodt, 1992; Stachour, 1998).

According to the stress-buffer hypothesis, stress leads to illness in a five-step causal chain, and social support can intervene at two points along that pathway (i.e., steps two and four) (Cohen \& Wills, 1985). In steps one and two, a potential stressor arises and an individual assesses the stressor given his/her resources (i.e., the appraisal process). The situation is appraised as stressful (step 
3) if an individual wants to respond to the stressor, but does not believe that he or she possesses the adequate resources to do so (with or without the help of others) (Lazarus \& Launier, 1978). In step four, an individual experiences a negative emotional response to stress, including feelings of helplessness and loss of self-esteem. In the last step, stress leads to illness and/or illness behaviors (e.g., drug and alcohol consumption, poor diet, \& lack of exercise).

Social support can help prevent stress by intervening during the stress appraisal step or emotional response to stress. First, during the stress appraisal step, social support can prevent the situation from being viewed as stressful. The perception that individuals within one's social support network will offer assistance leads to a reduction in the perceived threat of the stressful situation by bolstering one's perceived ability to deal with potential demands (Cohen \& McKay, 1984; Cohen $\&$ Wills, 1985). Second, social support can intervene during the emotional response to stress by reducing one's reaction to a stressful event. Social support works by "providing a solution to the problem, by reducing the perceived importance of the problem, [and] by tranquilizing the neuroendocrine system so that people are less reactive to perceived stress" (Cohen \& Wills, 1985, p. 312). In this respect, social support does not have a direct effect on the agent causing the stress. rather, it is a resource for individuals that influences their physiological response and behaviors (Stachour, 1998).

\section{Social Support for Doctoral Students}

Social support as a stress mediator has been explored in a number of contexts, but research is somewhat limited with regard to doctoral students (Cohen \& Wills, 1985; Hadjioannou, et al., 2007). The available research suggests that social support is an important resource for doctoral students. The following is a brief discussion of research related to social support for doctoral students.

Goplerud (1980) surveyed 22 psychology graduate students about their perceived levels of stress and social support during the first six months of their programs. Findings indicated that students who reported more support also reported less stress, health problems, and emotional problems. Additional research revealed that students who receive social support through regular interactions with their advisers tend to complete their degrees more quickly than students whose advisers do not provide as much feedback (Wao \& Onwuegbuzie, 2011).

Additional research took a more generalized approach. For example, Mallinckrodt and Leong (1992) surveyed 166 graduate students from various disciplines. Participants completed two social support assessments (i.e., Family Environment Support and Graduate Program Support) and two stress assessments (i.e., Stressful Life Events and Psychological Stress Symptoms). Findings were in agreement with Goplerud (1980) with regard to the stresses of graduate school. Findings also indicated that gender differences exist with regard to social support and stress for graduate students. More specifically, female graduate students experience less familial social support and more stress, while male students experience more familial social support and less stress. The researchers also suggested the need for future research to investigate the types of social support that is most beneficial for graduate students in achieving their goals. Castro, Garcia, Cavazos, and Castro (2011) also studied women's experiences as doctoral students. They determined that female doctoral students benefitted from individual characteristics such as "intrinsic motivation, independence, internal locus of control, resolve, perseverance, and motivating self' (p. 69). Their findings revealed that negative external factors can serve as positive motivation as well.

Other research expanded upon Mallinckrodt and Leong's (1992) study and included more doctoral students from a greater variety of disciplines. Hodgson and Simoni (1995) polled 566 doctoral students from various programs including humanities, social sciences, life sciences, and physical science. Participants answered questions about their financial status and completed two 
stress surveys (i.e., Graduate Life Events Scale and the Graduate Student Stress Survey) and a social support survey (i.e., Graduate Social Support Scale). Findings indicated the following: a) there is a negative relationship between reported social support and stress, and b) female doctoral students experience less support and more stress than male doctoral students.

Unlike the aforementioned studies, Lee (2009) surveyed individuals who had successfully completed a doctoral degree and were faculty members. Participants described the negative aspects of their doctoral experience. For example, they used descriptors like difficult, stressful, frustrating, and exhausting, and described their time spent as lonely, painful, and frightening. Some participants reported that it was "almost impossible" to balance the roles of academic career and doctoral student. Lee's findings also illuminated the factors that both enhanced and detracted from the respondent's doctoral experience. Among the enhancing factors were family support, involvement with other students, and a positive relationship with other faculty. The factors that detracted from their experience included multiple life responsibilities, financial issues, and difficulties with faculty and advisers.

The studies discussed above illustrate the importance of social support for doctoral students in alleviating stress and successful degree completion. Most of the available research on social support for doctoral students used self-report measures to quantitatively assess the students' perceived levels of social support and stress. Results suggest two main findings. First, doctoral students' social support networks are typically comprised of their adviser, family members, and peers (Council of Graduate Schools, 2005; Kerlin, 1997). Second, compared to students with less social support, students with more social support report less stress, health problems, and emotional problems, and (perhaps subsequently) better success rates (Goplerud, 1980; Hodgson \& Simoni, 1995; Mallinckrodt \& Leong, 1992).

However, the specific beneficial or detrimental behaviors from social support networks remain unclear. To assist future doctoral students, it is necessary to establish a detailed description of both beneficial and detrimental behavior so that we know which behaviors to promote or avoid (Mallinckrodt \& Leong, 1992). Hadjioannou et al. (2007) is one of the few studies that examined specific social support behaviors. The researchers were a group of five doctoral students from the same program. The authors initially banded together to form a study/support group. The authors state, "We made each other feel less old and tired, less inexperienced and foreign, less lonely and vulnerable" (Hadjioannou, et al., 2007, p. 175). Their support group later transitioned into their study, which focused on identifying the types of peer support that was helpful in completing their degrees. Findings highlighted the following types of peer support: a) teaching help; b) professional development in the academic community; c) help with academic work and writing; d) practical help in being a graduate student (i.e., procedures and regulations); and e) emotional support.

There were three limitations to Hadjioannou et al.'s (2007) study. First, the five doctoral students in the study (i.e., the researchers) were all from the same doctoral program. This limits the scope of the findings. Second, the researchers only focused on peer support. This leaves out important individuals who are commonly in a doctoral student's social support network, namely their family and faculty adviser (Kuyken, Peters, Powers, \& Lavender, 2003). Third, the researchers focused only on helpful behaviors. Thus, the scope of the findings is limited because it did not examine detrimental behaviors.

\section{Purpose of the Study}

The purpose of this study is to examine the social support networks of doctoral students who have successfully completed a doctoral degree. The present study addresses the limitations of the available research in three significant ways. First, doctoral students from various disciplines were included in this study to broaden the generalizability of the results. Second, doctoral student were 
asked to describe both the helpful and detrimental behaviors from individuals within their social support system. Third, participants were asked how they would change their social support system to make it more helpful. Overall, this study aims to assist future doctoral students by helping them to understand how social support systems function and how they can apply that knowledge to their own social support systems in order to successfully complete a doctoral degree. Our investigation was guided by the following two research questions:

RQ1: What behaviors from their social support networks would doctoral students report as beneficial in degree completion?

RQ2: What behaviors from their social support networks would doctoral students report as detrimental to degree completion?

\section{Method}

\section{Participants and Design}

Because the focus of this study was to understand how students experienced social support in their doctoral education, the authors used a qualitative research approach to answer the research questions. In order to understand the role of social support in completing a doctoral degree from a variety of perspectives, the authors used an open-ended, online, qualitative survey to collect the data. The online survey allowed the authors to obtain perspectives from respondents from multiple institutions; therefore, the authors were able to gain a greater understanding of the concept of social support (Hoffman \& Cowan, 2010). The authors obtained participants by using a convenience sample through Zoomerang, an online survey site. At the beginning of the fall semester, the authors sent emails to friends and colleagues who had successfully completed a doctoral degree, requesting that they complete the online survey. These potential participants were primarily 1) colleagues at the authors' current university, representing a variety of disciplines in the humanities and social sciences, and 2) people with whom the authors' attended graduate school in the disciplines of psychology and communication. The last question of the survey asked participants to provide email addresses of their colleagues and acquaintances who also might be willing to complete the survey. These potential participants represented a variety of disciplines which could generally be classified under the arts, humanities, and social sciences. Before emailing the survey to these participants, the authors validated that the participants held a doctoral degree.

This sampling technique yielded 31 participants with completed doctoral degrees from multiple universities in the United States. The participants ranged in age from 29 to 63, with the average age of the participants being 43 years old. The group of participants was primarily female, with 20 females and 11 males. Twenty-nine of the participants earned a Doctor of Philosophy degree (Ph.D.), two earned a Doctor of Education (Ed.D.), and one earned a Doctor of Musical Arts degree (D.M.A.). Participants represented 12 diverse academic disciplines, including communication $(n=11)$, technical communication $(n=1)$, education $(n=3)$, educational psychology $(n=3)$, psychology $(n=4)$, music $(n=1)$, linguistics $(n=1)$, English and creative writing $(n=2)$, American literature $(n=1)$, language education (second language acquisition) $(n=1)$, occupational and adult education $(\mathrm{n}=1)$, and art history $(\mathrm{n}=3)$. The ranks of the participants were as follows: five full professors, eight associate professors, eleven assistant professors, six lecturers/adjunct faculty, one administrator, and one indicated he was "not in academia."

To ensure that all participants defined social support in the same manner, they were first provided with the ffollowing definition of social support from Kaplan, Cassel, and Gore, (1977) and Thoits (1982): 
Social support is the degree to which a person's basic social needs are fulfilled by interacting with others. Social support systems can be comprised of individuals and/or groups. Social support systems may provide affection, sympathy, acceptance, esteem from others, advice, information, and help with work responsibilities.

Participants were asked a series of open-ended questions related to the social support they received in their doctoral education. They were then asked the following questions: 1) Please describe your social support system, 2) In what ways did your social support system help you complete your doctoral education?, 3) In what ways did your social support system hinder your degree completion?, and 4) In retrospect, what changes to your social support system would have improved your experience during your doctoral education?

\section{Data Analysis}

The authors used a grounded theory research design to analyze the data (Glaser \& Strauss, 1967; Strauss \& Corbin, 2008). Grounded theory provides a deep, rich analysis, allowing a communication situation to be clearly articulated (Strauss \& Corbin, 1998, 2008). The use of grounded theory is appropriate for the analysis of open-ended survey responses obtained via an online survey site, such as Zoomerang (see Hoffman \& Cowan, 2010). In keeping with a grounded theory research design, the authors analyzed the data to uncover themes. Grounded theory involves three stages of coding: open coding, axial coding, and selective coding. In order to determine the interrelatedness of the themes, the authors first engaged in open coding. In this process, the authors first independently analyzed the transcripts and considered each of the questions separately. The authors later met to discuss and identify emerging themes. In this phase, the authors worked to gain a general understanding of how doctoral students experienced social support. Second, the authors engaged in axial coding, in which they worked to find relationships among the categories that had begun to emerge. In this phase, the authors determined the themes that described which groups provided social support for doctoral students. Finally, to complete the analysis, the authors engaged in selective coding in which they developed their final interpretation of how doctoral students' experiences interrelate, forming a more complete picture of the function of social support in doctoral education. In this final phase, the authors determined how the groups provided social support and how the groups' actions impacted the eventual completion of a doctoral degree.

The process of grounded theory helps to ensure the equivalent of validity in qualitative research, often called trustworthiness (Lincoln \& Guba, 1985). Validity in qualitative research is "the degree to which the finding is interpreted in a correct way" (Kirk \& Miller, 1986, p. 20). In this case, the authors used purposive sampling (choosing participants based on a shared characteristic-a completed doctoral degree), posed questions that were directly related to that population's experiences with social support in doctoral education, and worked to reach data saturation, "the point at which no new data are being unearthed" (Strauss \& Corbin, 1998, p. 292).

\section{Results}

\section{Groups that Provide Social Support}

Participants indicated that their social support networks were comprised of three groups: academic friends, family, and doctoral advisers. The sources of social support corroborated previous research (Council of Graduate Schools, 2005; Kerlin, 1997). First, social support from academic friends came primarily from fellow graduate students who are often completing doctoral degrees in the same discipline as the participants. Second, social support from family came from spouses, children, siblings, and parents, with spouses playing a particularly important role. Third, social 
support from faculty came from the participants' advisers, doctoral committee members, and professors.

This study was guided by two research questions that asked doctoral students to describe behaviors exhibited by their social support network that were beneficial (i.e., positive social support) and those behaviors that were detrimental (i.e., negative social support) to degree completion. The follow sections discuss how doctoral students' academic friends, family, and faculty all behaved in ways that both positively and negatively influenced the students' degree progress.

\section{Positive Social Support}

The first research question pertained to behaviors that helped doctoral students with their degree completion. Overall, responses showed that one's social support network was vital to completing the doctorate. The importance of the social support network is illustrated by the following quote from a participant:

My social support system helped me tremendously during my doctoral program. I always felt I had support from many different angles, including friends, fellow graduate students, and professors. No matter the situation, I always had another person or group of people to share my feelings with. I trusted these people to give me good advice and to help me solve whatever problem I encountered.

The results also showed that there were three distinct types of positive social support, including emotional support, practical support, and professional support. Each social group (i.e., academic friends, family, and faculty) not only provided some level of emotional support but also provided a type of social support that was unique to that group. For example, academic friends and faculty each provided a unique form of professional support, and family members provided practical support. The following section describes the positive social support offered by each social group.

\section{Academic friends}

Participants discussed the support of their academic friends more than any other group. Participants indicated that academic friends provided two types of social support - emotional and professional support.

Emotional support. Emotional support is defined as an individual's attempts to alleviate negative affect in another person and shows caring for another person (Heller \& Rook, 1997; House, 1981). Examples of emotional support include active listening, empathy, and showing concern (Nelson \& Brice, 2008). Studies show emotional support from friends is the single most important factor in students' professional development (Singh \& Shifflette, 1996). Specifically, in this study, participants indicated that their academic friends provided emotional support in the following three ways: empathy, encouragement, and enjoyment. First, academic friends provided empathy. Participants indicated that their academic friends were able to understand precisely what participants were going through because academic friends were experiencing the same struggles and conflicts themselves. Participants discussed numerous ways in which fellow doctoral students provided empathy. Academic friends acted as sounding boards, allowing participants to vent about courses, research requirements, and struggles with professors. Participants stated that their academic friends "helped them through difficult times," "helped to put things in perspective," were "ready to listen to [them] when [they] was upset," and "gave perspectives regarding how to deal with stress." One participant described her interactions with her research group, saying that "we also spent several hours at each meeting airing our uncertainties and anxieties about the dissertation, talking about our career options, gossiping about colleagues, and simply chit-chatting. It was bliss!" Participants indicated that because academic friends understood the challenges and 
problems inherent in doctoral education, they could provide support directly focused on these problems.

Second, academic friends provided doctoral students with encouragement. Participants indicated that their academic friends made themselves available to each other on a regular basis to encourage their progress in the program and to celebrate professional successes. One participant stated that her academic friends "cheered me on when I was ready to quit or give up. They helped me to put things into perspective." Others discussed the encouragement academic friends in dissertation groups provided each other. One respondent demonstrated the importance of her dissertation group's encouragement:

We each graduated in a different year, and for each new Ph.D. we organized a celebration and pooled our money to buy an engraved sterling-silver bracelet or other memento as a gift. I was the third to finish, and celebrating the first two doctorates somehow helped make my own completion seem closer and more attainable.

Participants also discussed that their academic friends acted as cheerleaders, encouraging them to attain higher goals. Several discussed the fact that their academic friends "cheered for my individual successes professionally, such as publications." Others noted that their academic friends celebrated and supported each other as they met writing deadlines for publications, comprehensive exams, and dissertations.

The third type of emotional support doctoral students received from their academic friends is enjoyment. Participants indicated that an integral part of their successful completion of their doctoral programs was the socializing and fun activities that they engaged in with their academic friends. Many participants discussed the need for group activities, such as going out to eat, meeting at each other's homes, socializing over drinks on the weekends, going bowling, playing sand volleyball, or simply getting together to talk. In describing who provided enjoyment for her, a participant emphatically responded, "Fellow doctoral students! We would get together for wine and to whine." The responses indicated that the need for emotional support extends beyond the university walls. Participants noted that the group bonding activities, in which communication related to both academic and nonacademic issues, is necessary to build cohesion among doctoral students. Responses indicate that the enjoyment and fun they received through interaction with academic friends are a necessary part of coping with the rigors of a doctoral education.

Professional support. Professional support is defined as providing feedback, advice, and assistance in solving specific professional problems (Rosenholtz, 1989; Singh \& Billingsley, 1998). Academic friends provide advice about time and stress management, and they provide assistance with writing, research, and teaching issues. Participants indicated that support in writing and research was instrumental in assisting them in the composition of their dissertation. One participant stated:

The most critical support came from a dissertation group of three other female art historians in my graduate program. We met every 5-8 weeks or so for several years. For each meeting, we would read approximately one chapter of one member's dissertation ahead of time and write notes in the margins. At the meetings, we would devote at least hour, usually two or even three, to discussing the chapter(s)/paper and our comments. I would have completed my dissertation even without the group, but the final product wouldn't have been as good.

Many participants discussed the usefulness of their research/writing groups and the assistance that they provided. Participants discussed the fact that they sought out "study groups, social gatherings, paper presentations, and other such meetings with like-minded grad students to discuss academic research" because they recognized that "peer review, peer opinion, and sharing common 
experiences" would be of benefit to everyone involved. Several participants indicated that not only did they feel that they learned from each other through their interactions with these writing groups, but often the group members also provided inspiration for each other. One participant stated that the "intelligence, creativity, and accomplishments" of his writing group "inspired me."

\section{Family}

The participants' indicated that their family members provided two types of social supportemotional and practical support. Practical social support was only provided by participants' family members.

Emotional support. The type of emotional support from family differed from that offered by academic friends. Whereas emotional support from academic friends focused on doctoral students' specific problems and issues relating to school issues, familial emotional support dealt more with overall encouragement, esteem building, and love. In speaking about their families, participants provided the most information about their husbands, wives, or significant others. Many respondents stated that their significant others aided them emotionally by providing encouragement, friendship, and love. One stated that her husband "listened to my triumphs, joys, struggles, and frustrations. He was proud of my achievements." Another said that her husband "encouraged me and built my confidence." A third said that her husband acts as a calming force in her life, saying, "He not only helps me when I am stressed, but inspires me to be patient, kind, and calm." Therefore, familial emotional support seems vital to the emotional well-being of doctoral students.

Practical support. Practical support, also termed tangible support (Schaefer et al., 1981), includes gifts, financial support, and taking care of chores for someone else. Practical support is important for doctoral students because it has been shown to act as a buffer against depression and a negative morale (Schaefer et al., 1981). Participants indicated that their families provided financial support, assistance with housework, time and space to do work, and assistance with children. Regarding financial support, one stated that her husband, "worked full time so that I could go to school full time." Another respondent said that his wife "took care of the day-to-day items when I couldn't." Many respondents discussed the importance of the time that their significant others and children gave in order to provide assistance for doctoral students who simply did not have the time to do household duties. One stated that his family, "allowed me time to do things that I wouldn't have the time to do, such as doing the dishes, cooking meals, and cleaning the house so I could write." Respondents indicated that the practical support from their families allowed them the time necessary to complete the copious amounts of work associated with doctoral education. Additionally, families provided financial support necessary to engage in a doctoral program without having to take on excessive work responsibilities in addition to their studies.

\section{Faculty}

Participants indicated that faculty members provided two types of social support - emotional and professional support. Faculty support came from the following sources: 1) professors in their departments, 2) professors from other disciplines from whom doctoral students took classes, 3) professors who comprised their doctoral committees, and 4) their doctoral adviser. Although participants indicated that they received social support from each of these groups of professors, they overwhelmingly received the most support from their doctoral adviser. Therefore, the following section will focus on the social support that doctoral advisers provided.

Emotional support. Participants indicated that many advisers were willing to provide emotional support if advisees needed it and were open to receiving it. One respondent said that his adviser "supported me with encouragement, with assurances that my work was high-quality, with assur- 
ances that I'd made a good decision in deciding to pursue the Ph.D. in the first place." Another added, "I had the most amazingly supportive adviser that one could hope for. For those who did not have the support of their adviser like I did, I am not sure how they did it!" Clearly, respondents who had social support systems that provided positive social support recognized the important role of their adviser. Another participant responded:

My adviser ... was always very kind to me. She is a single mother of two, and I think she really felt for me when I got divorced and left an emotionally abusive, unfaithful man. She made sure I always had a research assistantship for as long as possible. She was a role model for being a single mother and academic, and she guided me with time management.

This same participant spoke compassionately of her teaching mentor, who passed away during the participant's time in graduate school. She discussed his support in terms of teaching her to have balance in her life. She stated:

He was my role model for how to be an academic and live a balanced life. All the other professors were SO focused on research that I watched their families suffer, be neglected, and simply become dysfunctional ... my teaching mentor was always balanced. Thankfully, I had a good four years to see how you can be a good professor, and have a great family. He brought warmth to the entire program.

Although emotional support from faculty might have been less frequent than from academic friends, it also centered on providing encouragement. The respondents reported that their advisers fulfilled the vital role of role model in managing both personal and professional affairs.

Professional support. Perhaps the most important type of support that doctoral advisers provide is professional support. Doctoral advisers are typically subject-matter experts in the doctoral students' areas of study and are, therefore, in a good position to offer feedback, advice, and problemfocused assistance. Responses indicated differences with regard to when the professional support from advisers was provided. Some respondents indicated that their advisers became part of their social support system early on in their doctoral education, while others indicated that their advisers began their roles in the support system shortly before the dissertation writing process. Regardless of the time of the advisers' entrance into the doctoral students' social support system, participants indicated that their advisers' expertise and knowledge were instrumental in their successful completion, especially in the writing of the dissertation. Many respondents stated that the knowledge-based guidance that their advisers provided them was crucial to their successful completion of the degree. Numerous respondents spoke of their advisers" "knowledge-based guidance" and their "content-area expertise." Overall, faculty members, especially doctoral advisers, strengthened doctoral students' social support systems.

\section{Negative Social Support}

The second research question that guided this study asked participants to describe the behaviors from their social support systems that were detrimental to doctoral degree completion. The results illustrate the contradictory nature of social support from academic friends, family, and faculty. Although the social support offered by the three social groups was largely beneficial, each of the groups simultaneously engaged in behaviors that hindered doctoral students' academic progress.

\section{Competition among academic friends}

Doctoral students often view other graduate students as competition that must be overcome in order to rise to the top of the class and to obtain coveted assistantships and more lucrative academic positions (Anderson \& Swazey, 1998). Participants in this study echoed this sentiment, saying that their academic friends and colleagues often made their experiences unpleasant be- 
cause of competition. One respondent stated, "I would like to see the elimination of competition between and among grad students." Another respondent elaborated, "As for my fellow grad students, at first, I think we saw each other, on some level, as competitors." Another participant commented that a fellow graduate student initially seemed like a welcome addition to her social support system, but later turned competitive. She explained:

Just as in any group, and especially graduate students, there was one person in particular who was particularly competitive. I would have not turned to her for support initially if I would have known how she would later make me feel.

Another agreed, saying:

Graduate work can bring [out] petty, passive-aggressive behaviors in people. I found myself being more mindful of those behaviors in myself (and trying to avoid them) and distancing myself from those who indulged them. I grew up (kind of) thanks to those people who valued and respected me and taught me to treat others similarly.

Therefore, competition exists among academic friends because they must compete for assistantships, advisers, their teachers' approval, and grades, and ultimately, academic positions, of which there are few. Competition among their peers hindered degree completion because it heightened their anxiety levels and induced a negative effect, which in turn negatively impacted their performance.

\section{Lack of understanding from family}

Numerous respondents stated that although their family members provided positive social support, family members often did not understand why doctoral students were pursuing a doctoral degree. Sternberg (1981) describes this lack of understanding by the general public, "American society is not aware ... of the larger-than-life trials, fortitude, despair, courage, and even heroics experienced in [doctoral education]" (p. 2). One respondent indicated a level of jealousy from her family, saying, "As the only person in my immediate family (parents and two siblings) to attend college, they don't understand what I do and believe I think I'm 'above' them." Other respondents indicated that their families did not understand what a doctoral degree is, why it is necessary, and what economic or professional opportunities it would provide for graduates. One respondent relived her attempts to explain to her family the utility of her degree, saying, "just because I don't make a product or fix a product, my job isn't made up." Several participants discussed lack of understanding of their family members in relation to the writing of a dissertation. One said:

My husband and mother could have had more faith in me to finish the dissertation. They mistook my perfectionism and laborious writing process for procrastination and an inability to complete the thesis. I always knew I would finish, but I never managed to convince my family, up until the day of my defense.

Interactions with family members, such as those described by the participants, often led to misunderstandings over responsibilities like housework and child-rearing. For example, a doctoral student might be working on her dissertation or homework and a family might not understand why she cannot help with chores around the house or putting the children to bed. These misunderstandings could take time away from a doctoral student that might otherwise have been spent on getting work done.

One respondent articulated well the ebb and flow of her family's social support. Similar to other respondents, she demonstrates how families sometimes build support, while, at other times, weaken the social support structures. She stated: 
My family started out somewhat supportive. As stress became a factor, they knew that they had to be supportive because "mom is crazy today." Their support came in wavesat times they were extremely supportive, but towards the end, they just wanted me done. When I passed my dissertation, my husband was out of town, and my children were still in bed when I got home. I told them I passed, they essentially said "okay," then went back to bed. My parents stated how proud they were, but did not attend graduation, a few months later. My sister who lives 50 miles away, said it was too far to come to graduation.

\section{Inappropriate communication from faculty}

Respondents reported that faculty members often do not initiate interpersonal relationships with doctoral students. Additionally, faculty often behave inappropriately by openly debating, imposing values, and communicating in a threatening manner with doctoral students. Respondents felt that such adversarial behavior by faculty created difficult working relationships and made doctoral students feel that they had to become hyper vigilant - a behavior that distracted from their primary focus - their academic work. One respondent stated:

I would have liked to have had professional behavioral models that revealed that you don't have to be underhanded and passive aggressive to be successful. Sometimes, we felt like animals at the watering hole and you had to be on the alert for predators constantly.

Study participants indicated that many faculty members and advisers often acted in a childish and even aggressive manner. One stated, "My adviser would make others cry with her bluntness." Another added, "When faculty behave like petulant children, students will likely model that behavior." Another commented about the inappropriate behavior in her department that resulted after an admired professor passed away, saying, "The department became cold, calculating, and lost that humanity." Respondents stated that their social support systems during their doctoral education would have been stronger if faculty had worked to model appropriate professional behavior. This negative and counterproductive communication among faculty members and doctoral students not only caused a distraction from the main goal of doctoral education, but also set poor examples for doctoral students who complete their degrees and take academic positions. Thus, doctoral students may be more likely to emulate this inappropriate behavior as future faculty members.

\section{Lack of professionally active faculty}

Many respondents stated that they would have experienced more success in their doctoral programs and in their current positions if their advisers would have been more involved in enhancing doctoral students' professional development. Numerous participants indicated that their doctoral advisers were not socially connected with their disciplines' national professional organizations. One respondent stated that because his adviser "was beginning his slide into retirement," he "didn't do a great job of helping me slip into the professional support systems that were operating." Another added that she wished that she "would have been able to meet more people in my field." Therefore, because of their advisers' social inactivity in their disciplines, respondents indicated that they were unable to become socially connected or forge relationships within their disciplines.

\section{Discussion}

The purpose of this research was to identify the types of positive and negative social support that doctoral students experience. The following four implications can be drawn from the results: 1) 
the findings support the stress-buffer hypothesis, 2) each social group provides both positive and negative support, 3) doctoral students provided suggestions for future doctoral students, and 4) doctoral students provided suggestions for faculty advisers. These implications will be discussed below, followed by limitations and directions for future research.

\section{Positive Social Support and the Stress-Buffer Hypothesis}

Stress is an accumulation of problems that strain one's problem-solving ability (Cohen \& Wills, 1985). Individuals experience greater stress when the situation involves multiple and persistent stressors, rather than a single event (Cohen \& Wills, 1985). Respondents of this study discussed how their doctoral study brought about multiple stressors, such as academic deadlines, teaching demands, research demands, caring for children, household duties, financial issues, and other family issues.

The positive support offered by the doctoral students' social support networks provide further evidence for the stress-buffer hypothesis and likely reduced their stress levels. Recall that Cohen and Wills (1985) proposed a five-step causal-chain that explains the link between stress and illness and/or illness behaviors. According to the stress-buffer hypothesis, social support can mediate stress by interjecting at two points along the causal-chain of stress-stress appraisal and emotional response (Cohen \& McKay, 1984).

First, social support mediates stress by preventing or influencing a stress appraisal. Individuals who perceive that others will provide necessary resources to manage a stressful situation will no longer appraise a situation as stressful. The respondents who had completed doctoral degrees in this study reported that their social support changed their perceptions of potential stressors. Professional support from academic friends and faculty advisers helped the doctoral students perceive stressors as less stressful. For example, the doctoral dissertation can be a particularly daunting task, and the respondents described in great detail how help from their peers and adviser was instrumental in reducing stress. Academic friends gathered in writing groups and advisers provided their content-based expertise and guidance. Practical support from family also helped with stress appraisal. Along with their academic, teaching, and research demands, the doctoral students also encountered demands of daily life, such as housework, chores, bills, and raising children. The respondents, however, described how assistance from family members alleviated the stressors of daily living because without their help, those demands would not have been met.

Second, social support can mediate stress by influencing one's emotional response even after an event occurs and it is appraised as stressful. In response to stress, one develops negative affect, including feelings of helplessness and loss of self-esteem. As Cohen and Wills (1985) write, "Feelings of helplessness arise because of the perceived inability to cope with situations that demand effective response (p. 312). Low of self-esteem results from one attributing his/her inability to cope with the stressful event to internal personality traits, rather than other external causes (Garber \& Seligman, 1980). All three social groups provided some degree of emotional support. The doctoral students' peers acted as proverbial cheerleaders, while their doctoral advisers provided reassurances about the quality of their work and their decision to pursue the degree. Emotional support from family helped to bolster the students' perceived ability to handle stress by providing self-esteem and confidence building.

Overall, the results of this study lend support for the stress-buffer hypothesis. As previously stated, stress is a major factor attributed to doctoral student attrition and those students who do stay in their programs report significantly higher levels of stress. Since social support is vital to degree completion, the possibility exists that those students who leave their programs might not have received adequate social support from academic friends, family, and faculty. 


\section{Positive and Negative Social Support from Each Source}

Results confirmed findings from previous research that doctoral students' social support networks are typically comprised of three social groups: academic friends, family, and faculty (Council of Graduate Schools, 2005; Kerlin, 1997). The results of this study also showed each group within doctoral students' social support networks provides both positive and negative social support. Academic friends, who are caring, empathetic, helpful allies, can also compete against each other and foster unnecessary competition with other doctoral students. Family members, who provide love, encouragement, and practical support, can also hinder doctoral students' progress through communicative behaviors associated with a lack of understanding of doctoral education. Faculty members, who use their expertise to guide a doctoral student through courses, comprehensive exams, publications, and dissertation writing, can also act inappropriately toward doctoral students by belittling their ideas and imposing their own values upon doctoral students.

\section{Recommendations for Future Doctoral Students}

The findings of this research can benefit future doctoral students in numerous ways. Based on doctoral students' responses, the authors offer the following suggestions which aim to maximize positive social support and minimize negative social support for future doctoral students.

\section{Academic friends}

Doctoral students are encouraged to form and maintain collegial relationships with academic friends, such as establishing small study groups. Doctoral students are uniquely positioned to provide their peers with social support because they have a shared experience. Their shared experience makes them better equipped to provide direct support. The respondents' descriptions of support from academic friends corroborates findings from previous research (Hadjioannou, et al., 2007; Singh \& Shifflette, 1996). Academic friends provide each other with encouragement, act as sounding boards, and help with research, writing, and coursework. Future doctoral students should be aware of the potential for competition among students and should be prepared when such a situation arises. For example, future doctoral students should be aware of the potential for competition among doctoral students and guard themselves against passive-aggressive behaviors that fellow doctoral students can display.

\section{Family}

Doctoral students are also encouraged to seek assistance from their family. While academic friends are in the unique position to provide direct help with coursework, families are in the unique position to provide financial help and to assist with household chores. The respondents described how the rigors of doctoral study made everyday activities, such as cleaning the house and taking care of children, seem impossible. Family members also provide their unique blend of emotional support that focused on love, sympathy, and encouragement.

However, many family members lack a clear understanding of what is required in completing a doctoral degree. This echoes the findings of previous research (Sternberg, 1981). Therefore, it would be beneficial for future doctoral students to explain the various doctoral requirements (such as the steps to writing a dissertation) to their family. Doing so might prevent some of the negative social support from family.

\section{Faculty}

Findings indicate that faculty should provide compassion and understanding when a doctoral student faces difficulty in the program and should provide advice to help a doctoral student attain a work/life balance. In addition, respondents indicated that advisers' practical support is invaluable 
because of their expertise and experience. The importance of the doctoral adviser corroborates findings from previous research (Kuyken et al., 2003). Therefore, future doctoral students are encouraged to establish rapport with their advisers early on, especially in light of the findings indicating that some advisers are slow to initiate contact. Respondents described the frustrations and difficulties they experienced when working with advisers who were less inclined to engage in research or had a limited professional network. Therefore, future doctoral students are also encouraged to select their advisers carefully.

\section{Recommendations for Doctoral Advisers}

Based on respondents' comments, the authors make the following recommendations for doctoral advisers to improve the social support that they provide to doctoral students. First, the doctoral students reported that faculty often engaged in negative communication and set poor examples for professional behavior. Some of the students reported that some faculty members' behavior created adversarial relationships that hindered their productivity. The respondents suggested that faculty members become more cognizant of their communication with each other and with doctoral students. Respondents stated that this inappropriate communication does have a large impact on them. Therefore, faculty members should realize that they can play a large role in making a positive impact.

Second, respondents reported that some advisers were unable to facilitate their professional development because their advisers did not maintain professional connections within their disciplines. For example, many doctoral students reported that their advisers did not maintain memberships to professional organization or attend research conferences. Participants suggested that future advisers maintain connections with their colleagues through conferences and professional organizations to inculcate the importance of developing professionally and to help doctoral students begin to form networks with established scholars in their areas.

Respondents also indicated that they would have appreciated more professional development within their departments. Respondents discussed their desire for faculty to set aside time for discussions, seminars, and/or luncheons to help doctoral students to discuss research and to improve as emerging scholars. One said, "I believe more structured gatherings (e.g. paper presentations) ... might have provided additional confidence-building and technical instruction." Another said that "Having workshops on dissertation writing might have been helpful."

\section{Limitations and Research Directions}

Limitations of this research relate to the data collection, method, and focus of the study. First, the authors used a convenience sample technique to recruit participants. Therefore, future research could involve wider pool of potential participants. Second, the authors collected data through the use of an online survey. Future research could conduct live interviews to gain more in-depth responses. Third, the authors focused doctoral students' perspective of social support. Future research could attempt to gain insight of all groups that comprise the social support system (e.g., academic friends, family, and faculty). Fourth, the authors did not ask respondents where they obtained their doctoral degrees or where they currently teach (i.e., Ph.D. granting institutions, teaching-focused colleges, junior colleges). Future research could examine if doctoral students require unique types of social support for research and teaching. Fifth, there was a range in the participants' age, rank, and year they earned their doctorate degree. Future research should explore if there are differences relating to current rank or graduation date. Last, the respondents of this study had specific suggestions on how to improve social support for doctoral students. Future research could implement one or more of these suggestions and quantitatively measure the perceived impact on current doctoral students. 


\section{References}

Ali, A., \& Kohun, F. (2006). Dealing with isolation feelings in IS doctoral programs. International Journal of Doctoral Studies, 1, 21-33. Retrieved from http://www.ijds.org/Volume1/IJDSv1p021-033Ali13.pdf

Ali, A., \& Kohun, F. (2007). Dealing with social isolation to minimize doctoral attrition: A four stage framework. International Journal of Doctoral Studies, 2, 33-49. Retrieved from http://www.ijds.org/Volume2/IJDSv2p033-049Ali28.pdf

Anderson, M., \& Swazey, J. P. (1998). Reflections on the graduate school experience: An overview. New Directions for Higher Education, 101, 3-13.

Berkman, L. F. (1995). The role of social relations in health promotion. Psychosomatic Medicine, 57, 245254.

Bowman, R. L., \& Bowman, V. E. (1990). Mentoring in a graduate counseling program: Students helping students. Counselor Education and Supervision, 30, 58-65.

Cahir, N., \& Morris, R.D. (1991). The psychology student stress questionnaire. Journal of Clinical Psychology, 47, 414-417.

Carnegie Classification of Institutions of Higher Education. (n.d.). Carnegie Foundation for the Advancement of Teaching. Retrieved March 1, 2012, from http://www.carnegiefoundation.org/

Castro, V., Garcia, E. E., Cavazos, J., Jr., \& Castro, A. Y. (2011). The road to doctoral success and beyond. International Journal of Doctoral Studies, 6, 51-77. Retrieved from http://ijds.org/Volume6/IJDSv6p051-077Castro310.pdf

Cohen, S., \& McKay, G. (1984). Stress, social support, and the buffering hypothesis: A theoretical analysis. In A. Baum, J. E. Singer, \& S. E. Taylor (Eds.), Social support: Theory, research, and applications. The Hague, Holland: Martinus Nijhoff.

Cohen, S., \& Wills, T. A. (1985). Stress, social support, and the buffering hypothesis. Psychological Bulletin, $98,330-357$.

Committee on the College Student, Group for the Advancement of Psychiatry. (2000). Helping students adapt to graduate school: Making the grade. New York, NY: Routledge.

Council of Graduate Schools. (2005). The doctor of philosophy degree: A policy statement. Washington, DC: Author.

Dirks, S. E., \& Metts, S. (2010). An investigation of the support process: Decision enactment, and outcome. Communication Studies, 61, 391-411.

Esping, A. (2010). Motivation in doctoral programs: A logotherapeutic perspective. The International Forum for Logotherapy, 33, 72-78.

Garber, J., \& Seligman, M. E. (1980). Human helplessness. New York: Academic Press.

Gilliam, J., \& Kitronis, W. A. (2006). National implications: The hidden nature of doctoral student attrition. National Journal for Publishing and Mentoring Doctoral Student Research, 3, 1-7.

Glaser, B. G., \& Strauss, A. L. (1967). The discovery of grounded theory: Strategies for qualitative research. New York: Aldine Publishing Company.

Golde, C. M. (1998). Beginning graduate school: Explaining first year doctoral attrition. In M. Anderson (Ed.), The experience of being in graduate school: An exploration (Vol. 101, pp. 55-64). San Francisco: Jossey-Bass Publishers.

Goplerud, E. N. (1980). Social support and stress during the first year of graduate school. Professional Psychology, 11, 283-290.

Hadjioannou, X., Shelton, N.R., Fu, D., \& Dhanarattigannon, J. (2007). The road to a doctoral degree: Cotravelers through a perilous passage. College Student Journal, 41, 160-177.

Hawlery, P. (2003). Being bright is not enough. Springfield, IL: Charles C Thomas. 
Heller, K., \& Rook, K. S. (1997). Distinguishing the theoretical functions of social ties: Implications for support interventions. In S. Duck (Ed.), Handbook of personal relationships: Theory, research, and interventions (2nd ed.) (pp. 649-670). New Jersey: Wiley.

Hodgson, C. S., \& Simoni, J. M. (1995). Graduate student academic and psychological functioning. Journal of College Student Development, 3, 244-253.

Hoffman, M. F., \& Cowan, R. L. (2010). Be careful what you ask for: Structuration theory and work/life accommodation. Communication Studies, 61, 205-223.

Hortulanus, R., Machielse M., \& Meeuwesen, L. (2006). Social isolation in modern society. New York, NY: Routledge.

House, J. S. (1981). Work stress and social support. Reading, MA: Addison-Wesley.

House, J. S., Landis, K. R., \& Umberson, D. (1988). Social relationships and health. Science, 24, 540-545.

Jackson, P. B. (1992). Specifying the buffering hypothesis: Support, strain, and depression. Social Psychology Quarterly, 55, 363-378.

Kasl, S. V. (1984). Stress and health. Annual Review of Public Health, 5, 319-341.

Kaplan, B. H., Cassel, J. C., \& Gore, S. (1977). Social support and health. Medical Care, 15, 47-58.

Kelly, M. (2005). Psychological adaptation to graduate school: How to smell the roses while burning the midnight oil. Behavior Therapist, 28, 57-59.

Kerlin, R. A. (1997). Breaking the silence: Towards a theory of women's doctoral persistence. Unpublished doctoral dissertation. University of Victoria, Canada.

Kirk, J., \& Miller, M. L. (1986). Reliability and validity in qualitative research. Newbury Park, CA: Sage Publications, Inc.

Kuyken, W., Peters, E., Powers, M. J., \& Lavender, T. (2003). Trainee clinical psychologists' adaptation and professional functioning: A longitudinal study. Clinical Psychology and Psychotherapy, 10, 41-54.

Lakey, B., \& Orehek, E. (2011). Relational regulation theory: A new approach to explain the link between perceived social support and mental health. Psychological Review, 118, 482-495.

Lazarus, R. S., \& Launier, R. (1978). Stress-related transactions between person and environment. In L. A. Pervis \& M. Lewis (Eds.), Perspectives in Interactional Psychology. New York: Plenum.

Lee, C. J. (2009). The experience of nurse faculty members enrolled in doctoral study. International Journal of Doctoral Studies, 4, 59-75. Retrieved from http://www.ijds.org/Volume4/IJDSv4p059075Lee255.pdf

Lewis, C. W., Ginsberg, R., Davies, T., \& Smith, K. (2004). The experiences of African American Ph.D. students at a predominantly white Carnegie I - research institution. College Student Journal, 38, 231245.

Lincoln, Y. S., \& Guba, E. G. (1985). Naturalistic inquiry. Beverly Hills, CA: Sage Publications.

Lovitts, B. E. (2001). Leaving the ivory tower: The causes and consequences of departure from doctoral study. Lanham, MD: Rowman \& Littlefield.

Mallinckrodt, B. (1992). International graduate students, stress, and social support. Journal of College Student Development, 33, 71-78.

Mallinckrodt, B., \& Leong, F. T. (1992). International graduate students, stress, and social support. Journal of College Student Development, 33, 71-78.

Nelson, M., \& Brice, J. (2008). Emotional and informational social support: Exploring contrasting influences of human resource management innovation. Journal of Organizational Culture, Communications, and Conflict, 12, 71-82. 
Reblin, M., \& Uchino, B. N. (2008). Social and emotional support and its implication for health. Current Opinions in Psychiatry, 21, 201-205.

Rosenholtz, S. J. (1989). Workplace conditions that affect teacher quality and commitment: Implications for teacher induction. The Elementary School Journal, 89, 421-439.

Schaefer, C., Coyne, J. C., \& Lazarus, R. S. (1981). The health-related functions of social support. Journal of Behavioral Medicine, 4, 381-406.

Schnurr, P. P., \& Green, B. L. (2004). Trauma and health: Physical health consequences of exposure to extreme stress. Washington, D.C.: APA.

Singh, K., \& Billingsley, B. S. (1998). Professional support and its effects on teachers' commitment. The Journal of Educational Research, 91, 229-239.

Singh, K, \& Shifflette, L. (1996). Teachers' perspective on professional development. Journal of Personnel Evaluation, 10, 143-158.

Stachour, V. (1998). The role of social support in mediating stress and illness. Honors Projects, Paper 57. http://digitalcommons.iwu.edu/psych_honproj/57

Sternberg, D. (1981). How to complete and survive a doctoral dissertation. New York, NY: St. Martin's Press.

Strauss, A. \& Corbin, J. (1998). Basics of qualitative research: Techniques and procedures for developing grounded theory (2nd ed.). Thousand Oaks, CA: Sage Publications, Inc.

Strauss, A. \& Corbin, J. (2008). Basics of qualitative research: Techniques and procedures for developing grounded theory (3rd ed.). Thousand Oaks, CA: Sage Publications, Inc.

Thoits, P.A. (1982). Conceptual, methodological, and theoretical problems in studying social support as a buffer against life stress. Journal of Health and Social Behavior, 23, 145-159.

Thoits, P. A. (2010). Stress and health: Major findings and policy implications. Journal of Health and Social Behavior, 51, S41-S53.

Walker, G., Golde, C. M., Jones, L., Bueschel, A. C., \& Hutchings, P. (2008). The formation of scholars: Rethinking doctoral education for the twenty-first century. Stanford, CA: Jossey-Bass.

Wao, H. O., \& Onwuegbuzie, A. J. (2011). A mixed research investigation of factors related to time to the doctorate in education. International Journal of Doctoral Studies, 6, 115-134. Retrieved from http://ijds.org/Volume6/IJDSv6p115-134Wao320.pdf

Weidman, J. C., Twale, D. J., \& Stein, E. L. (2001). Socialization of graduate and professional students in higher education: A perilous passage? ASHE-ERIC Higher Education Report, 28. San Francisco: Jossey-Bass. 


\section{Biographies}

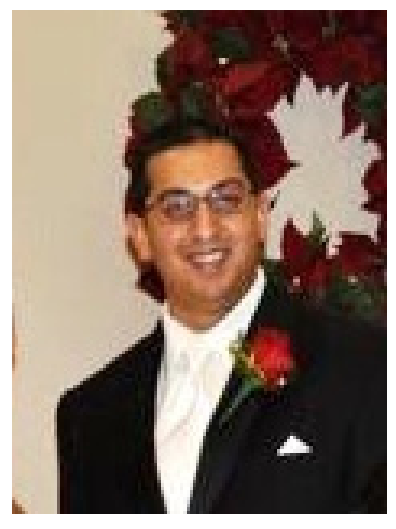

Dharmananda Jairam, Ph.D. is an Assistant Professor of Psychology at Penn State University-Erie. He earned his doctorate in Educational Psychology from the University of Nebraska-Lincoln. He also holds a Master's degree in counseling psychology from the State University of New York at Buffalo. He has published articles and a book chapter relating to human cognition and learning. He currently serves as a reviewer for several journals, and presents findings from his research at national conferences.

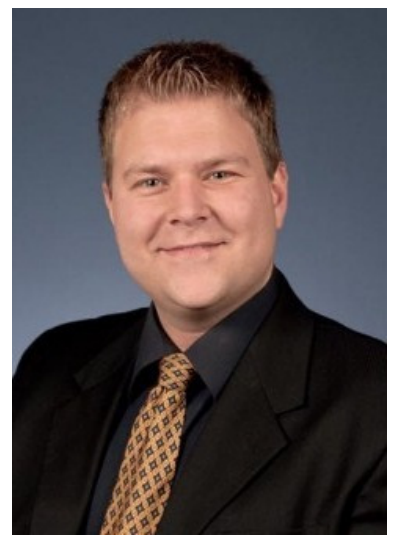

David H. Kahl, Jr., Ph.D. is an Assistant Professor of Communication at Penn State University-Erie. Because of his interests in pedagogy, Kahl primarily conducts research in the areas of communication education, instructional communication, and critical communication pedagogy. He is a frequent presenter at regional and national conferences, and has received research awards at both levels. Kahl has published numerous articles in regional, national, and international journals. Additionally, he serves as an invited reviewer for several journals and on the editorial board of a national communication journal, Communication Teacher. 